\title{
Comparative Study of Charge Trapping Type SOI-FinFET Flash Memories with Different Blocking Layer Materials ${ }^{\dagger}$
}

\author{
Yongxun Liu ${ }^{1{ }^{*},}$, Toshihide Nabatame ${ }^{2}$, Takashi Matsukawa ${ }^{1}$, Kazuhiko Endo ${ }^{1}$, \\ Shinichi O'uchi ${ }^{1}$, Junichi Tsukada ${ }^{1}$, Hiromi Yamauchi ${ }^{1}$, Yuki Ishikawa ${ }^{1}$, \\ Wataru Mizubayashi ${ }^{1}$, Yukinori Morita ${ }^{1}$, Shinji Migita ${ }^{1}$, Hiroyuki Ota ${ }^{1}$, \\ Toyohiro Chikyow ${ }^{2}$ and Meishoku Masahara ${ }^{1}$
}

1 National Institute of Advanced Industrial Science and Technology (AIST), 1-1-1 Umezono, Tsukuba, Ibaraki 305-8568, Japan; E-Mails: t-matsu@aist.go.jp (T.M.); endo.k@aist.go.jp (K.E.); shinichi.ouchi@aist.go.jp (S.O.); junichi-tsukada@aist.go.jp (J.T.); hiro-yamauchi@aist.go.jp (H.Y.); yuki.ishikawa@aist.go.jp (Y.I.); w.mizubayashi@aist.go.jp (W.M.); y.morita@aist.go.jp (Y.M.); s-migita@aist.go.jp (S.M.); hi-ota@aist.go.jp (H.O.); m.masahara@aist.go.jp (M.M.)

2 National Institute for Materials Science (NIMS), 1-1 Namiki, Tsukuba, Ibaraki 305-0044, Japan; E-Mails: NABATAME.Toshihide@nims.go.jp (T.N.); CHIKYO.toyohiro@nims.go.jp (T.C.)

$\dagger$ This is an extended version of paper "Charge Trapping Type FinFET Flash Memory with $\mathrm{Al}_{2} \mathrm{O}_{3}$ Blocking Layer" that was presented at the IEEE S3S Conference 2013.

* Author to whom correspondence should be addressed; E-Mail: yx-liu@aist.go.jp; Tel.: +81-29-861-3417; Fax: +81-29-861-5170.

Received: 28 February 2014; in revised form: 1 June 2014 / Accepted: 3 June 2014 / Published: 20 June 2014

\begin{abstract}
The scaled charge trapping (CT) type silicon on insulator (SOI) FinFET flash memories with different blocking layer materials of $\mathrm{Al}_{2} \mathrm{O}_{3}$ and $\mathrm{SiO}_{2}$ have successfully been fabricated, and their electrical characteristics including short-channel effect (SCE) immunity, threshold voltage $\left(\mathrm{V}_{\mathrm{t}}\right)$ variability, and the memory characteristics have been comparatively investigated. It was experimentally found that the better SCE immunity and a larger memory window are obtained by introducing a high- $\mathrm{Al}_{2} \mathrm{O}_{3}$ blocking layer instead of a $\mathrm{SiO}_{2}$ blocking layer. It was also confirmed that the variability of $\mathrm{V}_{\mathrm{t}}$ before and after one program/erase $(\mathrm{P} / \mathrm{E})$ cycle is almost independent of the blocking layer materials.
\end{abstract}


Keywords: charge trapping (CT); flash memory; silicon on insulator (SOI); FinFET; blocking layer; high-k metal gate; variability

\section{Introduction}

Device scaling is very effective for the fabrication of high-density and low-cost flash memories. However, further scaling of conventional bulk planar MOSFET type flash memories becomes very difficult because of the increased short-channel effect (SCE) and the lowered source-drain (SD) breakdown voltage $\left(\mathrm{BV}_{\mathrm{DS}}\right)$ with scaling down device size [1-3]. Especially, in the NOR-type flash memory, further scaling of device size faces the theoretical limit of $\mathrm{BV}_{\mathrm{DS}}$ which corresponds to the silicon $(\mathrm{Si})$ and silicon dioxide $\left(\mathrm{SiO}_{2}\right)$ conduction band difference $(3.2 \mathrm{eV})$. This indicates that channel hot electron (CHE) programming cannot be guaranteed in the scaled NOR-type flash memories with gate length $\left(\mathrm{L}_{\mathrm{g}}\right)$ smaller than $100 \mathrm{~nm}$ [2,3]. On the other hand, three-dimensional (3D) channel devices, such as fin-type double-gate (DG) MOSFET (FinFET) and fin-channel tri-gate (TG) device, provide excellent SCE immunity owing to the strong controllability of channel potential by the multiple gates [4-13]. Moreover, threshold voltage $\left(\mathrm{V}_{\mathrm{t}}\right)$ variability in the FinFETs and TG devices is much smaller than that in the conventional bulk planar MOSFETs because the random dopant fluctuation (RDF) induced $V_{t}$ variation is negligible in the FinFETs and $T G$ devices due to the undoped fin-channels [14-22]. Therefore, the scaled charge trapping (CT) type fin-channel flash memories using silicon on insulator (SOI)-based fin-channels and body-tied bulk Si fin-channels have actively been developed [23-32]. However, a high-k blocking layer is strongly required in the ultimately scaled CT type flash memory fabrication to overcome the gate coupling area decrease with scaling down the device size [33]. As a high-k blocking layer, an $\mathrm{Al}_{2} \mathrm{O}_{3}$ layer has been used in the planar MOSFET type and body-tied bulk FinFET type flash memories $[28,34]$. By introducing such a high-k blocking layer, the gate injection current is effectively suppressed during program/erase $(\mathrm{P} / \mathrm{E})$ operations because the electric field across the blocking layer is proportionally reduced owing to its high dielectric constant, which is useful for the enlarging of memory window. However, the blocking layer material effect on the electrical characteristics of SOI-FinFET flash memories has not been studied sufficiently. Very recently, we have demonstrated floating gate (FG) type split-gate fin-channel flash memories with a highly suppressed over erase, and experimentally confirmed that nanosize triangular cross-section tunnel areas are useful for the fabrication of the low operating voltage flash memories owing to the enhanced local electric field at the tips of triangular tunnel areas [35-38]. We have also fabricated and investigated FG type crystalline and polycrystalline Si fin-channel flash memories with DG and TG structures, and confirmed that TG structured flash memory shows the better SCE immunity and a larger memory window than the DG structured one owing to the additional top gate and recessed buried oxide (BOX) region [39-41]. Moreover, we have also investigated the gate material effect on the electrical characteristics of the CT type SOI-FinFET flash memories by introducing different gate materials of physical vapor deposited (PVD) titanium nitride (TiN) and $\mathrm{n}^{+}$-poly-Si [42]. It was experimentally found that a larger memory window is obtained in the PVD-TiN metal gate flash memories 
than the $\mathrm{n}^{+}$-poly-Si gate ones owing to the higher work function of PVD-TiN metal gate, which is efficient to suppress electron back tunneling during erase operation [28,34].

As a further study, in this work, we fabricate CT type SOI-FinFET flash memories with different blocking layer materials of atomic layer deposited (ALD) $\mathrm{Al}_{2} \mathrm{O}_{3}$ and chemical vapor deposited (CVD) $\mathrm{SiO}_{2}$, and comparatively investigate their electrical characteristics including SCE immunity, $\mathrm{V}_{\mathrm{t}}$ variability and memory characteristics [43].

\section{Device Fabrication}

In order to investigate the blocking layer material effect on the electrical characteristics and memory properties of the CT type SOI-FinFET flash memories, we fabricated MANOS (PVD-TiN Metal- $\mathrm{Al}_{2} \mathrm{O}_{3}$-Nitride-Oxide-Silicon) type and MONOS (PVD-TiN Metal-Oxide-Nitride-Oxide-Silicon) type TG structured SOI-FinFET flash memories. Figure 1 shows the schematic three-dimensional (3D) device structure for the CT type SOI-FinFET flash memory. Except for the deposition of blocking layer materials, the same process was used in the fabrication for both types of devices. To fabricate an ideal rectangular cross-section Si-fin-channel by using the orientation-dependent wet etching, we used lightly doped p-type (110)-oriented SOI wafers as the starting material [7,8]. The initial thicknesses of the top silicon and BOX layers were 70 and $145 \mathrm{~nm}$, respectively.

Figure 1. Schematic three-dimensional (3D) device structure for the CT type SOI-FinFET flash memory with different blocking layer materials of $\mathrm{Al}_{2} \mathrm{O}_{3}$ and $\mathrm{SiO}_{2}$.

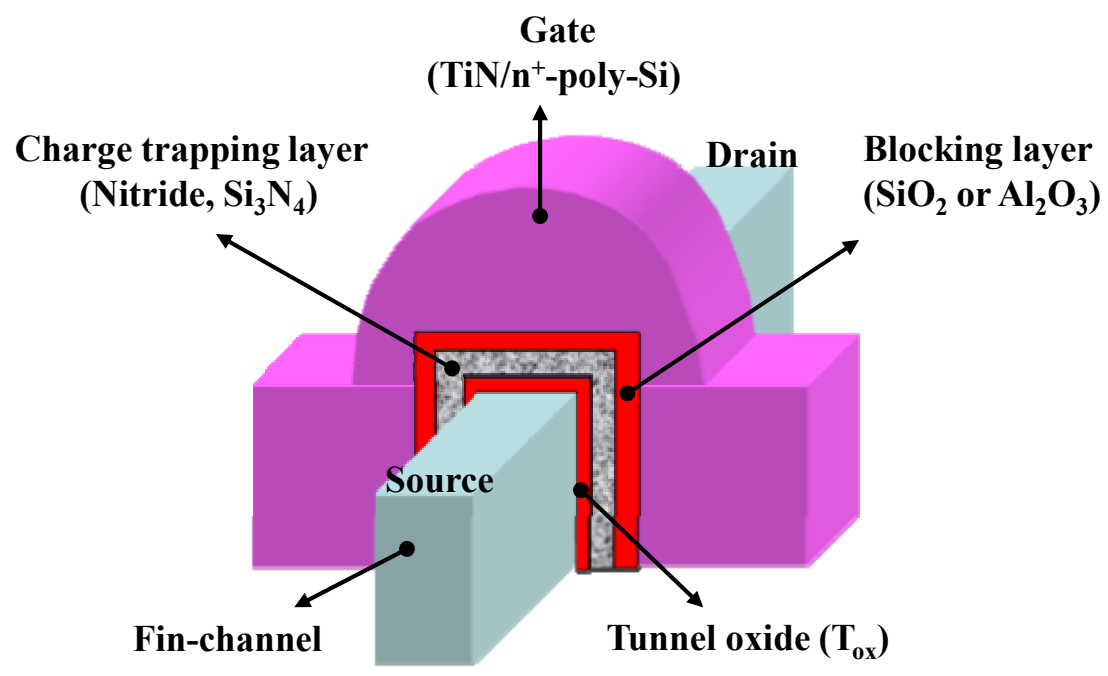

The schematic device fabrication process flow for the CT type SOI-FinFET flash memory is shown in Figure 2. First, the lightly doped p-type (110)-SOI wafers were thermally oxidized to form a 30-nm-thick $\mathrm{SiO}_{2}$ layer as shown in Figure 2a, and fin-patterns were delineated in parallel to the $<112>$ direction by using electron-beam (EB) lithography as shown in Figure $2 b$. The trimming of EB-resist was performed using oxygen plasma to reduce the fin width. The fin-patterns were then transferred to the $\mathrm{SiO}_{2}$ layer on the (110)-SOI wafers by reactive ion etching (RIE). After removing the EB-resist, further narrowing of the width of $\mathrm{SiO}_{2}$ hard-mask was carried out with dilute hydrofluoric acid (DHF) solution. By using these techniques, the width of $\mathrm{SiO}_{2}$ hard-mask was controlled to around $20 \mathrm{~nm}$. 
Figure 2. Schematic device fabrication process flow for the CT type SOI-FinFET flash memory. (a) Thermal oxidation; (b) fin-pattern formation by electron-beam (EB) lithography; (c) fin-channel formation by the orientation-dependent wet etching; (d) $\mathrm{SiO}_{2}$ hard-mask removing by RIE; (e) tunnel oxide $\left(\mathrm{T}_{\mathrm{ox}}\right)$ formation by thermal oxidation; (f) nitride $\left(\mathrm{Si}_{3} \mathrm{~N}_{4}\right)$ layer deposition by LPCVD; (g) blocking layer $\left(\mathrm{Al}_{2} \mathrm{O}_{3}\right.$ for MANOS and $\mathrm{SiO}_{2}$ for MONOS) deposition; (h) PVD-TiN deposition; (i) $\mathrm{n}^{+}$-poly-Si deposition.

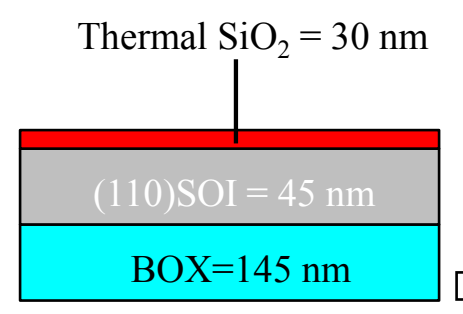

(a)

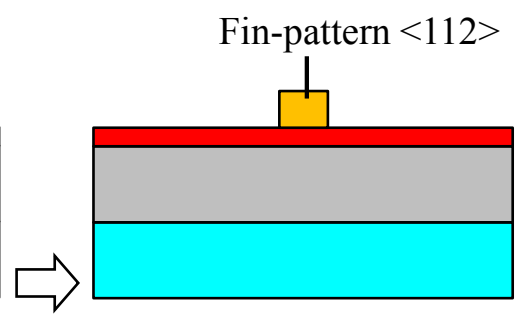

(b)

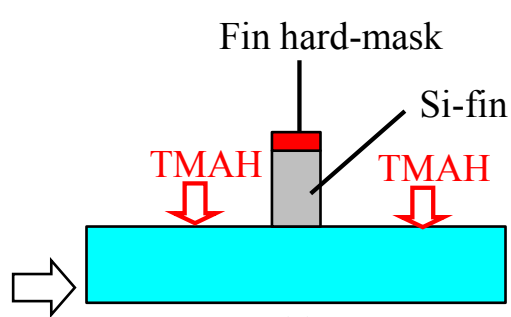

(c)

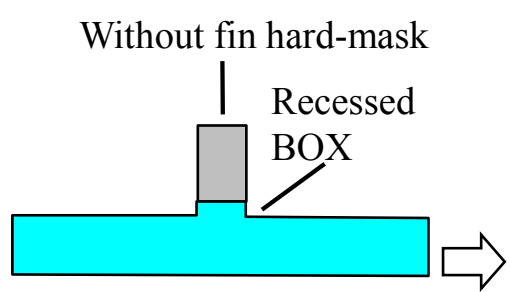

(d)

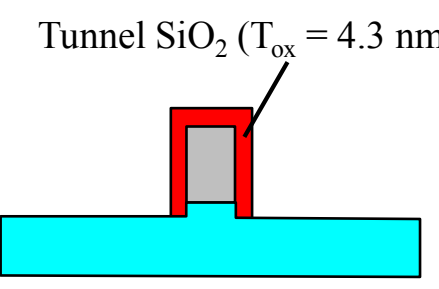

(e)

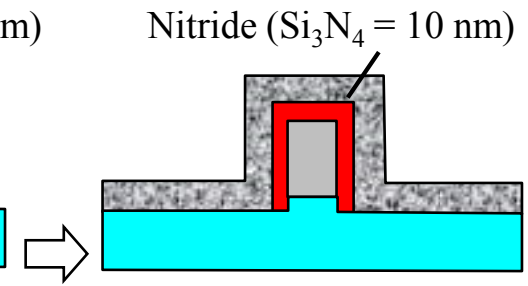

(f)

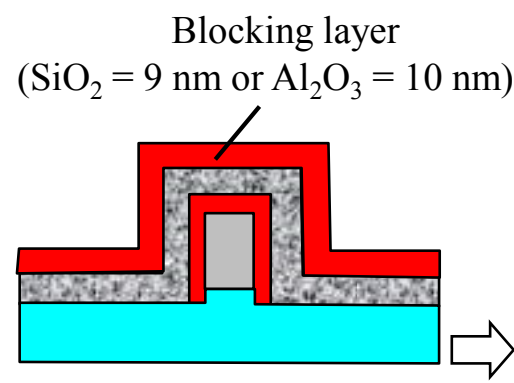

(g)

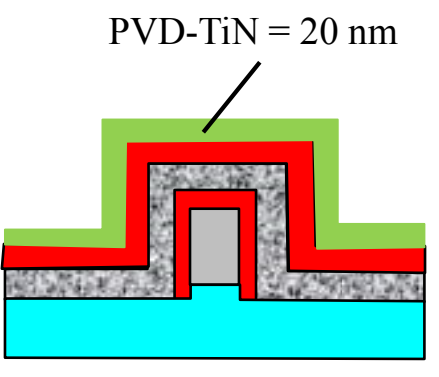

(h)

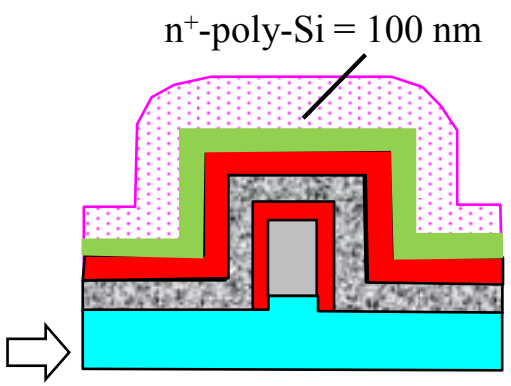

(i)

Through the $\mathrm{SiO}_{2}$ hard-masks, fin-channels were fabricated by the orientation-dependent wet etching with a $2.38 \%$ tetramethylammonium hydroxide (TMAH) solution at $50{ }^{\circ} \mathrm{C}$ for $30 \mathrm{~s}$, as shown in Figure 2c. Since the sidewalls of the fin-channels have a (111)-oriented plane with an extremely low etching rate in TMAH compared with other planes, very narrow and straight fin-channels can easily be fabricated. It was experimentally confirmed that the etching rates for (100)-, (110)-, and (111)-oriented Si wafers were 214,359 , and $9 \mathrm{~nm} / \mathrm{min}$, respectively [44]. This indicates that the (111) plane is successfully retained in the etching process. To fabricate $\mathrm{TG}$ structure, the $\mathrm{SiO}_{2}$ hard-mask layer was removed by RIE as show in Figure 2d, which results in a slight reduction of fin-height. A recessed BOX region was also formed in this RIE process, which is useful for the suppression of SCE [39-41].

After the fin-channel formation, a 4.3-nm-thick tunnel oxide $\left(\mathrm{T}_{\mathrm{ox}}\right)$ layer was formed by thermal oxidation at $850{ }^{\circ} \mathrm{C}$ as shown in Figure 2e, followed by the deposition of a 10-nm-thick $\mathrm{Si}_{3} \mathrm{~N}_{4}$ layer as the charge trapping layer by low-pressure chemical vapor deposition (LPCVD) at $790{ }^{\circ} \mathrm{C}$ as shown in Figure $2 \mathrm{f}$. As the blocking layer, a 9-nm-thick tetraethylorthosilicate (TEOS)- $\mathrm{SiO}_{2}$ layer was deposited for MONOS type devices by plasma CVD at $350{ }^{\circ} \mathrm{C}$, and a 10 -nm-thick $\mathrm{Al}_{2} \mathrm{O}_{3}$ layer was deposited for 
MANOS type device by atomic layer deposition (ALD) at $300{ }^{\circ} \mathrm{C}$ as shown in Figure $2 \mathrm{~g}$. In the ALD deposition, we used trimetylaluminum (TMA) and water gas at pressure of $14 \mathrm{hPa}$. As the same gate material, a combination of a 20-nm-thick PVD-TiN layer and a 100-nm-thick $\mathrm{n}^{+}$-poly-Si layer, was deposited on all wafers as shown in Figure $2 \mathrm{~h}$,i. The gate electrodes were also patterned by EB lithography and fabricated by using combination of inductively coupled plasma (ICP) RIE for $\mathrm{n}^{+}$-poly-Si and wet etching for PVD-TiN. In the PVD-TiN wet etching, we used an ammonium hydroxide $\left(\mathrm{NH}_{4} \mathrm{OH}\right)$ :hydrogen peroxide $\left(\mathrm{H}_{2} \mathrm{O}_{2}\right)$ :deionized water $\left(\mathrm{H}_{2} \mathrm{O}\right)=1: 2: 5(\mathrm{APM})$ solution at $60{ }^{\circ} \mathrm{C}$, which provides a high etching selectivity of PVD-TiN to $\mathrm{SiO}_{2}[45,46]$.

After etching the top ONA and ONO layers on the fin extension and SD electrode regions by RIE, arsenic (As) ion implantation (I/I) was performed for SD-extension with a dose $(D)$ of $4 \times 10^{14} \mathrm{~cm}^{-2}$ and a tilting angle $(\theta)$ of $60^{\circ}$ at a fixed implant energy of $5 \mathrm{keV}$ [47]. Then, an 80-nm-thick gate sidewall spacer was formed by deposition of TEOS-SiO ${ }_{2}$ and RIE. For the SD-region I/I, phosphorus ion $\left(\mathrm{P}^{+}\right)$was used with $D=1.5 \times 10^{15} \mathrm{~cm}^{-2}$ and $\theta=7^{\circ}$, which was followed by the deposition of a 100-nm-thick TEOS-SiO 2 layer on all wafers. To activate the implanted impurities, rapid thermal annealing (RTA) was performed at $830{ }^{\circ} \mathrm{C}$ for $2 \mathrm{~s}$. Finally, contact holes and aluminum electrodes were formed, and all wafers were sintered in forming gas ambient at $450{ }^{\circ} \mathrm{C}$ for $30 \mathrm{~min}$.

\section{Results and Discussion}

The scanning electron microscopy (SEM) images of the fabricated MANOS type SOI-FinFET flash memory after fin-channel formation and gate formation are shown in Figure 3a,b, respectively. Note that a straight 22-nm-thick Si-fin channel is successfully fabricated thanks to the orientation-dependent wet etching. Moreover, a scaled 26-nm gate is also clearly confirmed.

Figure 3. SEM images of the fabricated CT type SOI-FinFET flash memory (a) after fin-channel formation by the orientation-dependent wet etching and (b) after gate formation.

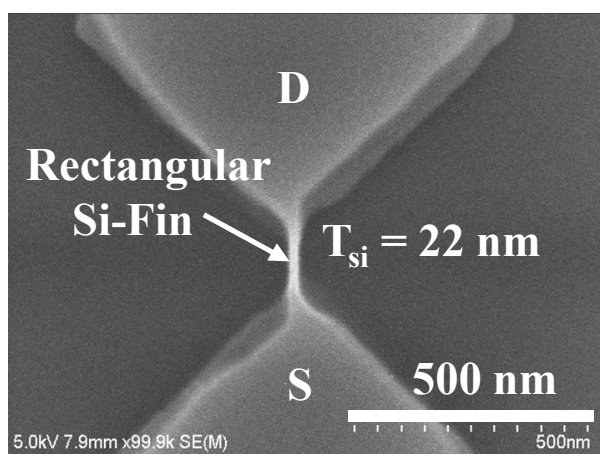

(a)

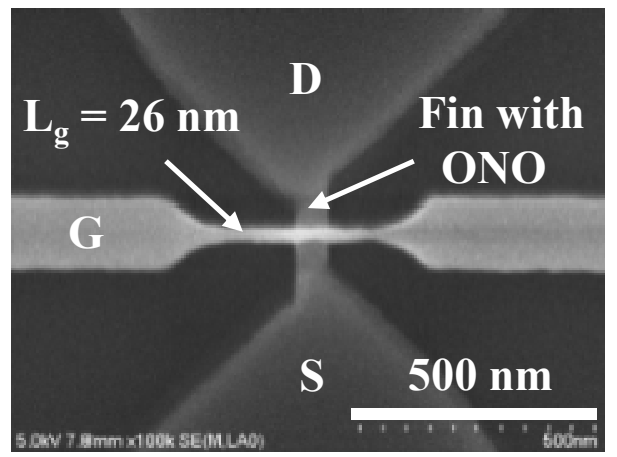

(b)

Figure $4 \mathrm{a}, \mathrm{b}$ show the cross-sectional scanning transmission electron microscopy (STEM) images of the fabricated MANOS and MONOS type SOI-FinFET flash memories, respectively. Note that ultrathin and ideal rectangular cross-sectional Si fin-channels are fabricated uniformly. It should be mentioned that the fin-width and fin-height were slightly narrowed and lowered during wafer cleaning and tunnel oxide formation. Moreover, it is clearly confirmed that a uniform tunnel oxide layer is formed on top and sidewalls of the fin-channels without a thick $\mathrm{SiO}_{2}$ hard-mask on top of $\mathrm{Si}$ 
fin-channel. This indicates that TG structure is fabricated successfully. Furthermore, it can be seen from STEM images that the charge trapping ONA and ONO layers are not only formed around the top and sidewalls of the fin-channels but also extended to the recessed BOX region. Such a gate all around (GAA) like structure is useful to the suppression of SCE as mentioned before. The observed a thin $\mathrm{SiO}_{2}$ blocking layer $(<9 \mathrm{~nm})$ in Figure $4 \mathrm{~b}$ probably depends on the pick-up position of STEM sample owing to the poor uniformity of $\mathrm{TEOS}-\mathrm{SiO}_{2}$ layer thickness on a wafer although a 9-nm-thick TEOS-SiO 2 layer was confirmed on a dummy wafer as mentioned before.

Figure 4. Cross-sectional STEM images of the fabricated (a) MANOS type SOI-FinFET flash memory with an $\mathrm{Al}_{2} \mathrm{O}_{3}$ blocking layer; and (b) MONOS type SOI-FinFET flash memory with a $\mathrm{SiO}_{2}$ blocking layer.

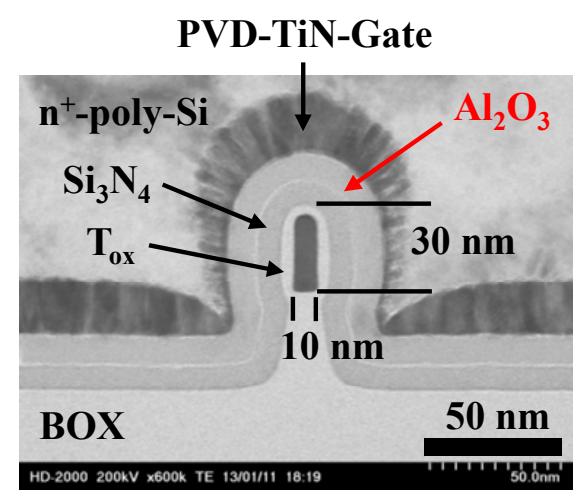

(a)

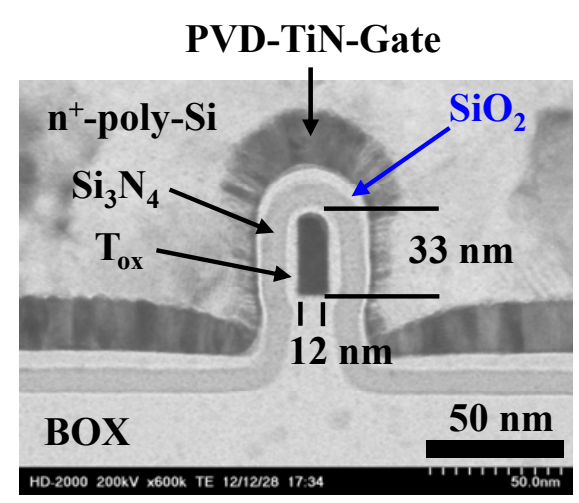

(b)

At first, we evaluated the $\mathrm{V}_{\mathrm{t}}$ variability and SCE immunity for the fabricated MANOS and MONOS type SOI-FinFET flash memories with different gate length $\left(\mathrm{L}_{\mathrm{g}}\right)$ values from 26 to $103 \mathrm{~nm}$. Figure 5a,b show the measured initial $\mathrm{I}_{\mathrm{d}}-\mathrm{V}_{\mathrm{g}}$ characteristics of the fabricated MANOS type flash memories with different $\mathrm{L}_{\mathrm{g}}$ values of 26 and $38 \mathrm{~nm}$, respectively. In this measurement, we used 40 cell transistors for each type to investigate statistical $V_{t}$ variations. Note that an excellent S-slope of $105-\mathrm{mV} /$ decade is obtained even $\mathrm{L}_{\mathrm{g}}$ is scaled down to $26 \mathrm{~nm}$ due to the GAA like structure. However, the uniformity of $\mathrm{I}_{\mathrm{d}}-\mathrm{V}_{\mathrm{g}}$ curve is slightly deteriorated with scaling down $\mathrm{L}_{\mathrm{g}}$ from 38 to $26 \mathrm{~nm}$.

To evaluate $\mathrm{V}_{\mathrm{t}}$ variations quantitatively, we measured the initial $\mathrm{V}_{\mathrm{t}}$ values at a constant drain current of $I_{d}=1 \mu$ A for all devices with different $L_{g}$ values from 26 to $103 \mathrm{~nm}$. Figure 6 shows the measured standard deviations of $\mathrm{V}_{\mathrm{t}}\left(\sigma \mathrm{V}_{\mathrm{t}}\right)$ and S-slope $(\sigma \mathrm{S})$ as a function of $\mathrm{L}_{\mathrm{g}}$ for the fabricated MANOS and MONOS type SOI-FinFET flash memories. It is clear that almost the same $\sigma \mathrm{V}_{\mathrm{t}}$ and $\sigma \mathrm{S}$ are obtained for both types of devices although they increase slightly with scaling down $\mathrm{L}_{\mathrm{g}}$. This result indicates that the variations of $\mathrm{V}_{\mathrm{t}}$ and S-slope are almost independent of the blocking layer materials. The measured average $\mathrm{V}_{\mathrm{t}}\left(<\mathrm{V}_{\mathrm{t}}>\right)$ ) and $\mathrm{S}$-slope $(<\mathrm{S}>)$ values are summarized as a function of $\mathrm{L}_{\mathrm{g}}$ as shown in Figure 7. Note that the smaller $\mathrm{V}_{\mathrm{t}}$ roll-off and the better $\mathrm{S}$-slope are obtained in the MANOS devices than the MONOS ones at whole range of $\mathrm{L}_{\mathrm{g}}$ due to the high-k effect of $\mathrm{Al}_{2} \mathrm{O}_{3}$ in MANOS type devices. 
Figure 5. Initial $I_{d}-V_{g}$ characteristics of the fabricated MANOS type SOI-FinFET flash memories with different $\mathrm{L}_{\mathrm{g}}$ values of (a) $\mathrm{L}_{\mathrm{g}}=26 \mathrm{~nm}$ and (b) $\mathrm{L}_{\mathrm{g}}=38 \mathrm{~nm}$.

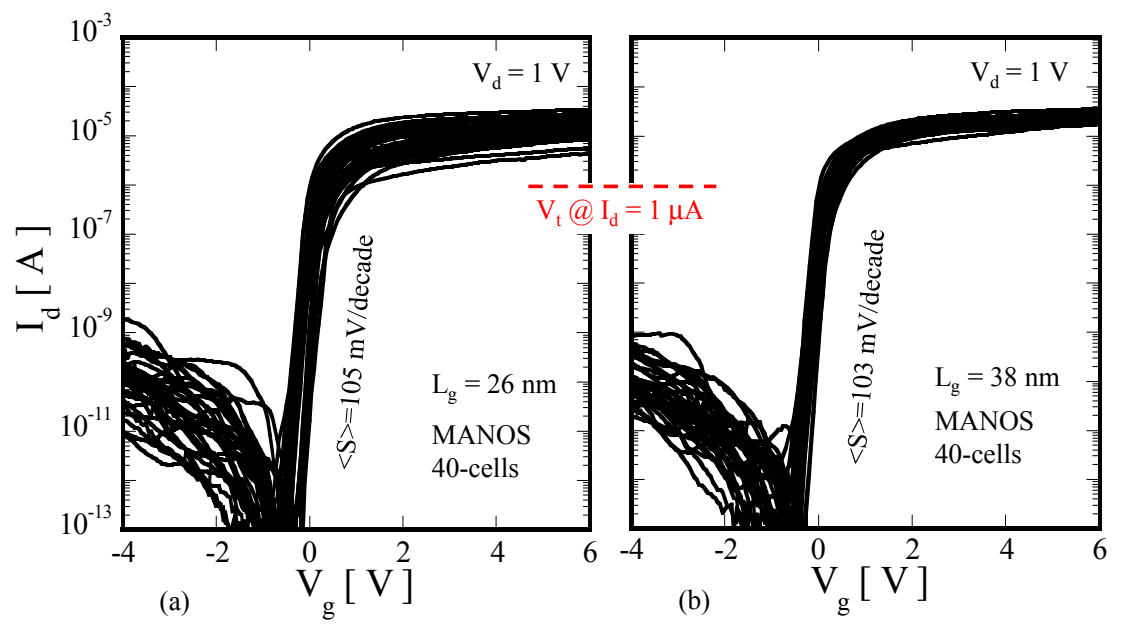

Figure 6. $\sigma \mathrm{V}_{\mathrm{t}}$ and $\sigma \mathrm{S}$ as a function of $\mathrm{L}_{\mathrm{g}}$ for the fabricated MANOS and MONOS type SOI-FinFET flash memories.

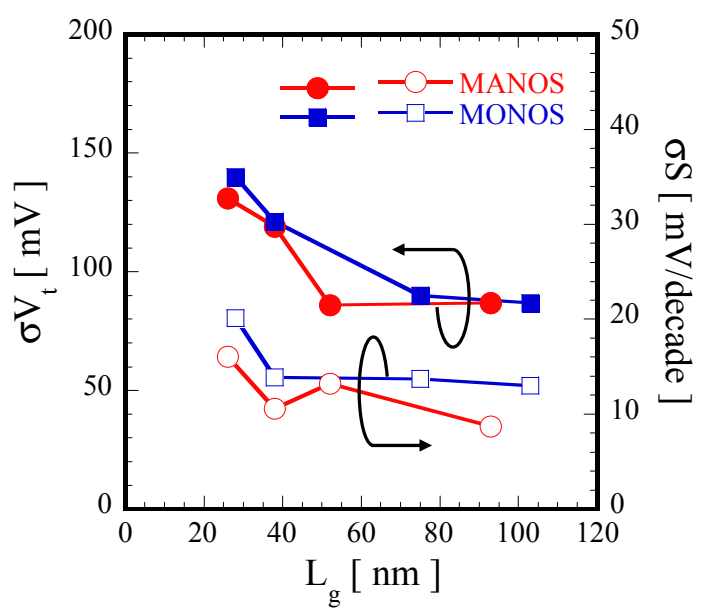

Figure 7. Average $\left.V_{t}\left(<V_{t}\right\rangle\right)$ and $S$-slope $(<S>)$ values as a function of $L_{g}$ for the fabricated MANOS and MONOS type SOI-FinFET flash memories.

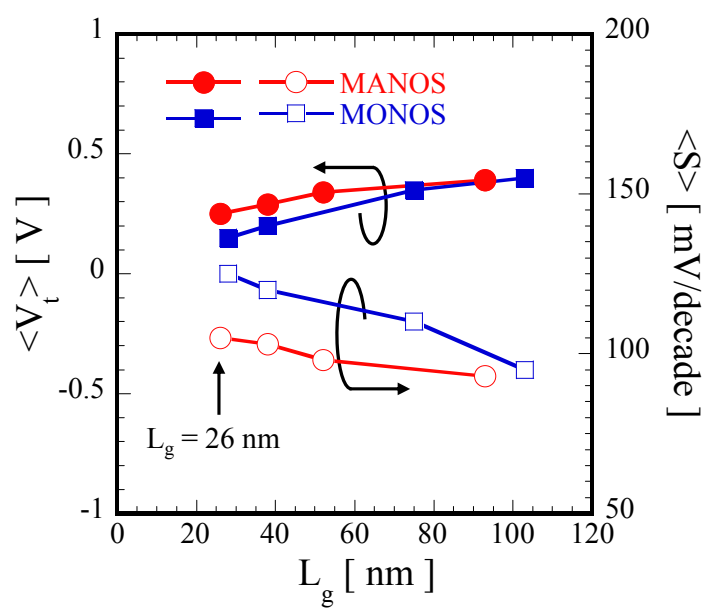


Before evaluation of memory characteristics, gate breakdown voltage was measured for the fabricated MANOS and MONOS type SOI-FinFET flash memory cell transistors. It was found that the gate breakdown voltage is around $17 \mathrm{~V}$. According to this experimental result, $\mathrm{P} / \mathrm{E}$ bias conditions were determined as $\mathrm{V}_{\mathrm{g}}=16 \mathrm{~V}$, pulse-time $(\mathrm{t})=50 \mu \mathrm{s}$ for programming, $\mathrm{V}_{\mathrm{g}}=-16 \mathrm{~V}, \mathrm{t}=20 \mathrm{~ms}$ for erasing. In order to evaluate the dependence of the memory characteristics on the blocking layer materials, including $V_{t}$ variability and memory window, the $I_{d}-V_{g}$ characteristics of the fabricated MANOS and MONOS type devices with different $\mathrm{L}_{\mathrm{g}}$ values were systematically investigated after one $\mathrm{P} / \mathrm{E}$ cycle. Figure $8 \mathrm{a}, \mathrm{b}$ show the measured $\mathrm{I}_{\mathrm{d}}-\mathrm{V}_{\mathrm{g}}$ characteristics of the fabricated MANOS type flash memory cell transistors with different $\mathrm{L}_{\mathrm{g}}$ values of 26 and $38 \mathrm{~nm}$ after one P/E cycle, respectively. In this measurement, we used 40 cell transistors for each type. It is clear that a larger memory window is reasonably obtained in the long channel devices as compared to the short channel devices. A similar behavior was also observed in the MONOS type devices.

To compare the $V_{t}$ variations between MANOS and MONOS type devices, $V_{t}$ values for all fabricated devices were also evaluated at a constant drain current of $I_{d}=1 \mu \mathrm{A}$. As an example, Figure 9 shows the measured cumulative probability of $\mathrm{V}_{t}$ and $\sigma \mathrm{V}_{t}$ values for the MANOS and MONOS type devices with the same $\mathrm{L}_{\mathrm{g}}$ of $38 \mathrm{~nm}$ after one $\mathrm{P} / \mathrm{E}$ cycle. Note that a larger memory window is obtained in the MANOS type devices than the MONOS type ones due to the high-k effect of $\mathrm{Al}_{2} \mathrm{O}_{3}$ blocking layer in MANOS type devices. However, it is clear that $\sigma \mathrm{V}_{\mathrm{t}}$ values for both devices are almost the same although slightly smaller $\sigma \mathrm{V}_{\mathrm{t}}$ values are observed in the MONOS type device than MANOS type one. Such comparison was also carried out for all fabricated MANOS and MONOS type devices with different $\mathrm{L}_{\mathrm{g}}$ values, and it was confirmed that actually a larger memory window is obtained in the MANOS type devices than the MONOS type ones at whole range of $\mathrm{L}_{\mathrm{g}}$ as shown in Figure 10. The deep erase in MANOS type devices should be resulted from the high-k effect of an $\mathrm{Al}_{2} \mathrm{O}_{3}$ $(\mathrm{k} \sim 9)$ blocking layer, which is efficient to enhance the electric field across the tunnel oxide and to reduce the electric field across the layer its self. Therefore, the electron back tunneling is effectively suppressed during erase operation which contributes to the deep erase in MANOS type devices [28,34].

Figure 8. $I_{d}-V_{g}$ characteristics of the fabricated MANOS type SOI-FinFET flash memory cell transistors (40 cells) with different $\mathrm{L}_{\mathrm{g}}$ values of (a) $\mathrm{L}_{\mathrm{g}}=26 \mathrm{~nm}$ and (b) $\mathrm{L}_{\mathrm{g}}=38 \mathrm{~nm}$. P/E conditions: $V_{g}=16 \mathrm{~V}, \mathrm{t}=50 \mu$ s for program, and $\mathrm{V}_{\mathrm{g}}=-16 \mathrm{~V}, \mathrm{t}=20 \mathrm{~ms}$ for erase.

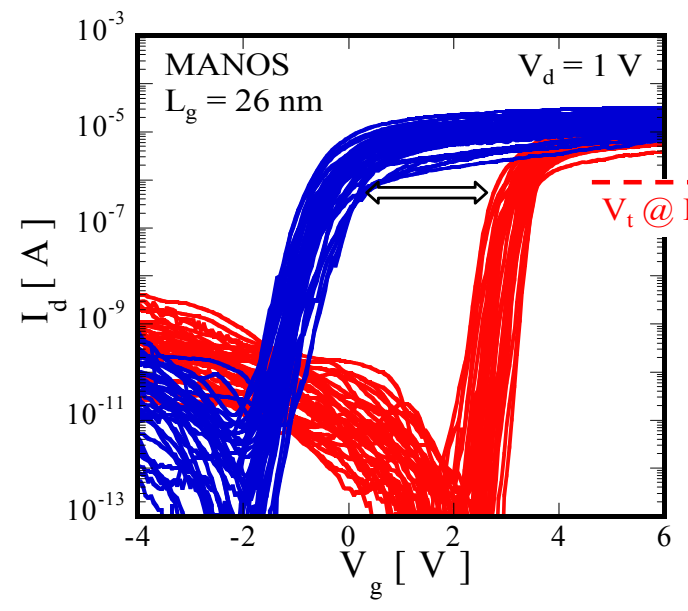

(a)

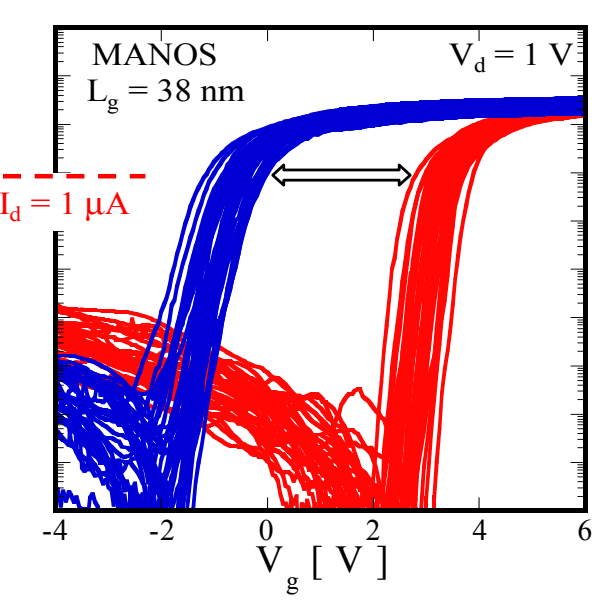

(b) 
Figure 9. (a) Cumulative probability of $V_{t}$ and (b) $\sigma V_{t}$ of the fabricated MANOS and MONOS type SOI-FinFET flash memories with the same $\mathrm{L}_{\mathrm{g}}$ of $38 \mathrm{~nm}$ after one $\mathrm{P} / \mathrm{E}$ cycle. P/E conditions: $V_{g}=16 \mathrm{~V}, \mathrm{t}=50 \mu \mathrm{s}$ for program, and $\mathrm{V}_{\mathrm{g}}=-16 \mathrm{~V}, \mathrm{t}=20 \mathrm{~ms}$ for erase.

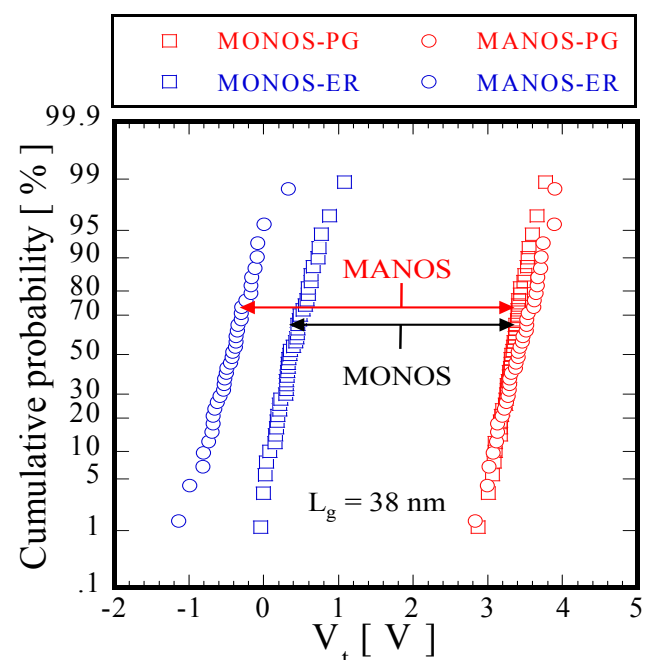

(a)

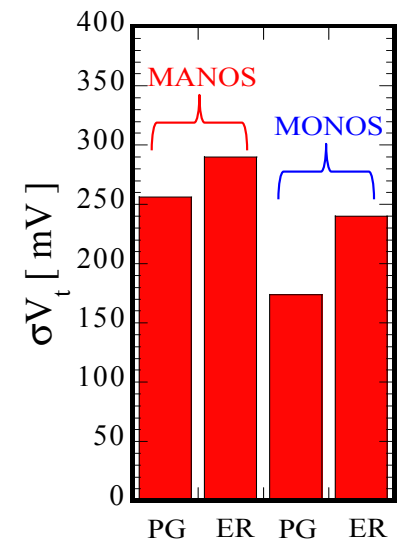

(b)

Figure 10. Average $V_{t}\left(\left\langle V_{t}\right\rangle\right)$ values as a function of $L_{g}$ for the fabricated MANOS and MONOS type SOI-FinFET flash memory cell transistors after one $\mathrm{P} / \mathrm{E}$ cycle. $\mathrm{P} / \mathrm{E}$ conditions: $\mathrm{V}_{\mathrm{g}}=16 \mathrm{~V}, \mathrm{t}=50 \mu$ s for program, and $\mathrm{V}_{\mathrm{g}}=-16 \mathrm{~V}, \mathrm{t}=20 \mathrm{~ms}$ for erase.

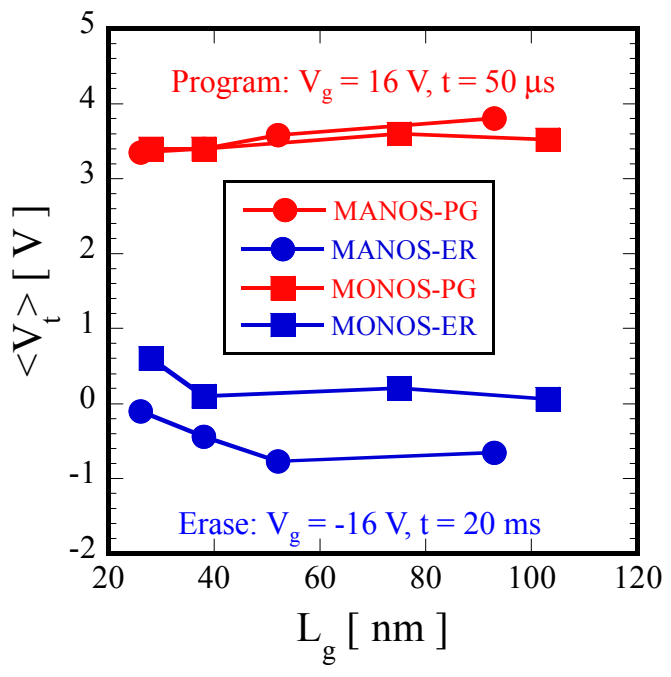

Figure 11a shows the measured $\mathrm{P} / \mathrm{E}$ characteristics of the fabricated MANOS type device with $\mathrm{L}_{\mathrm{g}}$ of $93 \mathrm{~nm}$ at different $\left|V_{g}\right|$ values, and the program-time dependence of the $I_{d}-V_{g}$ characteristics at $V_{g}$ of $14 \mathrm{~V}$ is shown in Figure 11b. It is clear that a large memory window of $5.6 \mathrm{~V}$ is obtained keeping an excellent S-slope of 100-mV/decade due to the GAA like structure. Figure 12a,b show the measured endurance characteristics of the fabricated MANOS and MONOS type devices, respectively. Note that these two kinds of device can operate over $100 \mathrm{k}$ cycles although somewhat remarkable degradation is observed in the MONOS type device after $10 \mathrm{k}$ cycles probably due to the insufficient uniformity of $\mathrm{CVD}-\mathrm{SiO}_{2}$ blocking layer. Moreover, the better data retention is obtained in the MANOS type device than MONOS type one due to the uniform $\mathrm{ALD}-\mathrm{Al}_{2} \mathrm{O}_{3}$ blocking layer as shown in Figure 13. 
Figure 11. (a) $\mathrm{P} / \mathrm{E}$ characteristics and (b) program-time dependence of the $I_{d}-V_{g}$ characteristics of the fabricated MANOS type SOI-FinFET flash memory with $\mathrm{L}_{\mathrm{g}}=93 \mathrm{~nm}$.

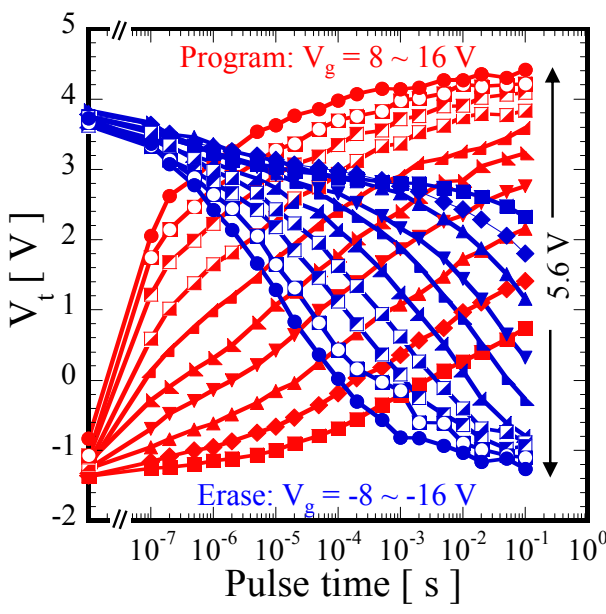

(a)

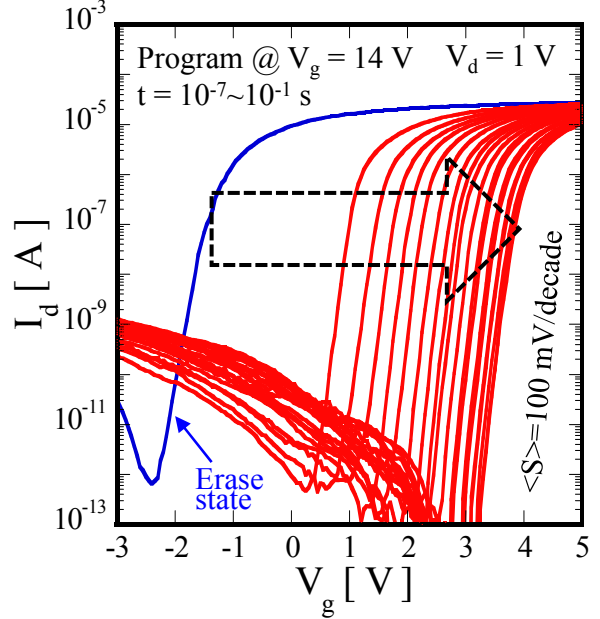

(b)

Figure 12. Endurance characteristics of the fabricated (a) MANOS type SOI-FinFET flash memory with $\mathrm{L}_{\mathrm{g}}=93 \mathrm{~nm}$; and (b) MONOS type SOI-FinFET flash memory with $\mathrm{L}_{\mathrm{g}}=103 \mathrm{~nm}$.

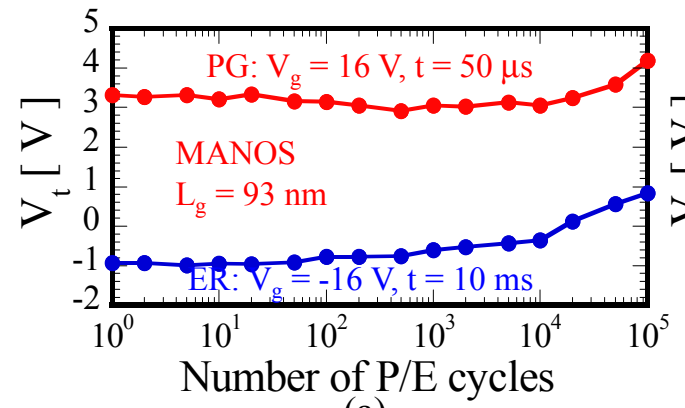

(a)

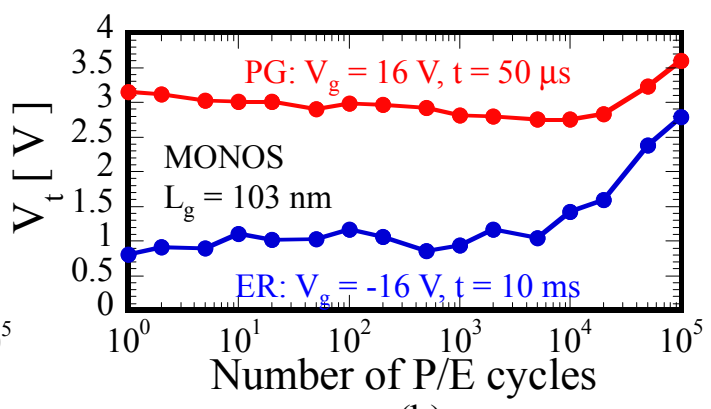

(b)

Figure 13. Retention characteristics of the fabricated MANOS type SOI-FinFET flash memory with $\mathrm{L}_{\mathrm{g}}=93 \mathrm{~nm}$ and MONOS type SOI-FinFET flash memory with $\mathrm{L}_{\mathrm{g}}=103 \mathrm{~nm}$ at room temperature.

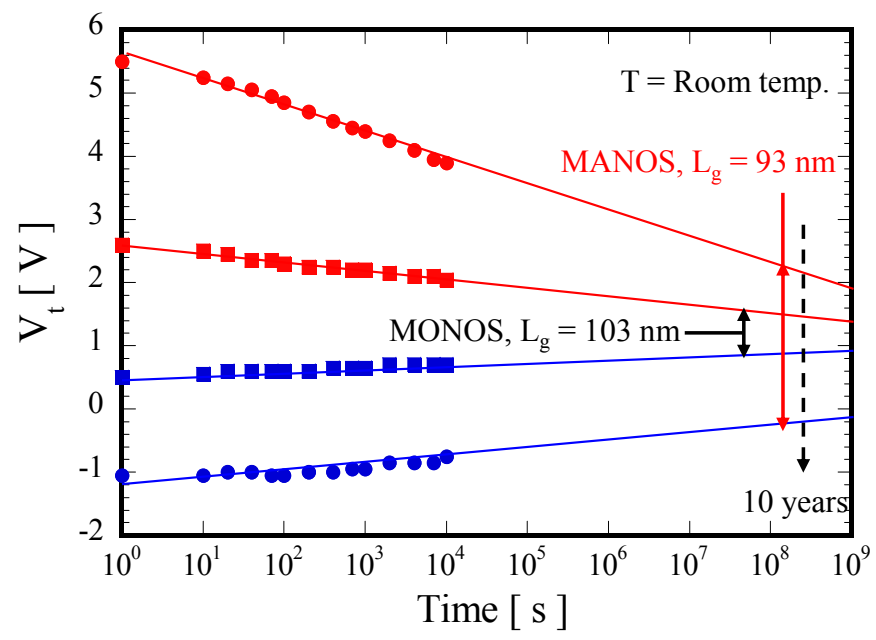




\section{Conclusions}

We have comparatively investigated the electrical characteristics and memory properties of the fabricated charge trapping type SOI-FinFET flash memories with different blocking layer materials of $\mathrm{Al}_{2} \mathrm{O}_{3}$ and $\mathrm{SiO}_{2}$. It was experimentally found that introducing a high-k $\mathrm{Al}_{2} \mathrm{O}_{3}$ blocking layer instead of a $\mathrm{SiO}_{2}$ one is very efficient for the enlarging of memory window owing to the high-k effect of $\mathrm{Al}_{2} \mathrm{O}_{3}$. It was also confirmed that $\mathrm{V}_{\mathrm{t}}$ variability before and after one $\mathrm{P} / \mathrm{E}$ cycle is almost independent of blocking layer materials.

\section{Acknowledgments}

This work was supported in part by the Nanotechnology Project of NEDO, Japan. The authors would like to thank Num Nguyen and Takeshi Inoshita of National Institute for Materials Science (NIMS) for fruitful discussions.

\section{Conflicts of Interest}

The authors declare no conflict of interest.

\section{References}

1. Xuan, P.; She, M.; Harteneck, B.; Liddle, A.; Bokor, J.; King, T.-J. FinFET SONOS Flash Memory for Embedded Applications. In Proceedings of the IEEE International Electron Devices Meeting, Washington, DC, USA, 8-10 December 2003; pp. 609-612.

2. Kim, T.-Y.; Cho, E.S.; Cho, H.J.; Sung, S.-K.; Lee, C.-H.; Choi, B.Y.; Cho, B.K.; Park, D.G. $256 \mathrm{Mb}$ FinFET NOR Flash Memory for sub-70 nm Technology Breakthrough. In Proceedings of the International Silicon Nanoelectronics Workshop, Kyoto, Japan, 12-13 June 2005; pp. 98-99.

3. Sim, S.-P.; Kim, K.S.; Lee, H.K.; Han, J.I.; Kwon, W.H.; Han, J.H.; Lee, B.Y.; Jung, C.; Park, J.H.; Kim, D.J.; et al. Fully 3-Dimensional NOR Flash Cell with Recessed Channel and Cylindrical Floating Gate-A Scaling Direction for $65 \mathrm{~nm}$ and Beyond. In Proceedings of the Symposium on VLSI Technology, Honolulu, HI, USA, 13-15 June 2006; pp. 22-23.

4. Hisamoto, D.; Lee, W.-C.; Kedzierski, J.; Takeuchi, H.; Asano, K.; Kuo, C.; Anderson, E.; King, T.-J.; Boker, J.; Hu, C. FinFET-A self-aligned double-gate MOSFET scalable to $20 \mathrm{~nm}$. IEEE Trans. Electron Devices 2000, 47, 2320-2325.

5. Choi, Y.-K.; Lindert, N.; Xuan, P.; Tang, S.; Ha, D.; Anderson, E.; King, T.-J.; Bokor, J.; Hu, C. Sub-20 nm CMOS FinFET Technologies. In Proceedings of the IEEE International Electron Devices Meeting, Washington, DC, USA, 2-5 December 2001; pp. 421-424.

6. Yu, B.; Chang, L.; Ahmed, S.; Wang, H.; Bell, S.; Yang, C.-Y.; Tabery, C.; Ho, C.; Xiang, Q.; King, T.-J.; et al. FinFET Scaling to $10 \mathrm{~nm}$ Gate Length. In Proceedings of the IEEE International Electron Devices Meeting, San Fransico, CA, USA, 8-11 December 2002; pp. 251-254.

7. Liu, Y.X.; Ishii, K.; Tsutsumi, T.; Masahara, M.; Takashima, H.; Suzuki, E. Ideal Rectangular Cross-Section Si-Fin Channel Double-Gate MOSFETs Fabricated Using Orientation-Dependent Wet Etching. IEEE Electron Device Lett. 2003, 24, 484-486. 
8. Liu, Y.X.; Masahara, M.; Ishii, K.; Tsutsumi, T.; Sekigawa, T.; Takashima, H.; Yamauchi, H.; Suzuki, E. Flexible Threshold Voltage FinFETs with Independent Double Gates and an Ideal Rectangular Cross-Section Si-Fin Channel. In Proceedings of the IEEE International Electron Devices Meeting, Washington, DC, USA, 8-10 December 2003; pp. 986-988.

9. Masahara, M.; Liu, Y.X.; Sakamoto, K.; Endo, K.; Matsukawa, T.; Ishii, K.; Sekigawa, T.; Yamauchi, H.; Tanoue, H.; Kanemaru, S.; et al. Demonstration, Analysis, and Dvice Design Cosiderations for Independent DG MOSFETs. IEEE Trans. Electron Devices 2005, 52, 2046-2053.

10. Liu, Y.X.; Matsukawa, T.; Endo, K.; Masahara, M.; Ishhi, K.; O’uchi, S.; Yamauchi, H.; Tsukada, J.; Ishikawa, Y.; Suzuki, E. Advanced FinFET CMOS Technology: TiN-Gate, Fin-Height Control and Asymmetric Gate Insulator Thickness 4T-FinFETs. In Proceedings of the IEEE International Electron Devices Meeting, San Fransico, CA, USA, 11-13 December 2006; pp. 989-992.

11. Doyle, B.; Boyanov, B.; Datta, S.; Doczy, M.; Hareland, S.; Jin, B.; Kavalieros, J.; Linton, T.; Rios, R.; Chau, R. Tri-Gate Fully-Depleted CMOS Transistors: Fabrication, Design and Layout. In Proceedings of the Symposium on VLSI Technology, Kyoto, Japan, 12-14 June 2003; pp. 133-134.

12. Yang, F.-L.; Chen, H.-Y.; Chen, F.-C.; Chan, Y.-L.; Yang, K.-N.; Chen, C.-J.; Tao, H.-J.; Choi, Y.-K.; Liang, M.-S.; Hu, C. $35 \mathrm{~nm}$ CMOS FinFET. In Proceedings of the Symposium on VLSI Technology, Honolulu, HI, USA, 13-15 June 2002; pp. 104-105.

13. Endo, K.; O’uchi, S.; Ishikawa, Y.; Liu, Y.X.; Matsukawa, T.; Sakamoto, K.; Tsukada, J.; Ishii, K.; Yamauchi, H.; Suzuki, E.; et al. Enhancing SRAM Cell Performance by Using Independent Double-Gate FinFET. In Proceedings of the IEEE International Electron Devices Meeting, San Fransico, CA, USA, 15-17 December 2008; pp. 857-860.

14. O’uchi, S.; Matsukawa, T.; Endo, K.; Liu, Y.X.; Sekigawa, T.; Tsukada, J.; Ishikawa, Y.; Yamauchi, H.; Ishii, K.; Suzuki, E.; et al. Characterization of Metal-Gate FinFET Variability Based on Measurements and Compact Model Analyses. In Proceedings of the IEEE International Electron Devices Meeting, San Fransico, CA, USA, 15-17 December 2008; pp. 709-712.

15. Matsukawa, T.; O’uchi, S.; Endo, K.; Ishikawa, Y.; Yamauchi, H.; Liu, Y.X.; Tsukada, J.; Sakamoto, K.; Masahara, M. Comprehensive Analysis of Variability Sources of FinFET Characteristics. In Proceedings of the Symposium on VLSI Technology, Kyoto, Japan, 15-17 June 2009; pp. 118-119.

16. Endo, K.; O’uchi, S.; Ishikawa, Y.; Liu, Y.X.; Matsukawa, T.; Sakamoto, K.; Tsukada, J.; Yamauchi, H.; Masahara, M. Variability analysis of TiN metal-gate FinFETs. IEEE Electron Device Lett. 2010, 6, 546-548.

17. Liu, Y.X.; Endo, K.; O’uchi, S.; Kamei, T.; Tsukada, J.; Yamauchi, H.; Ishikawa, Y.; Hayashida, T.; Sakamoto, K.; Matsukawa, T.; et al. On the Gate-Stack Origin Threshold Voltage Variability in Scaled FinFETs and Multi-FinFETs. In Proceedings of the Symposium on VLSI Technology, Honolulu, HI, USA, 13-15 June 2010; pp. 101-102.

18. Matsukawa, T.; Liu, Y.X.; O’uchi, S.; Endo, K.; Tsukada, J.; Yamauchi, H.; Ishikawa, Y.; Ota, H.; Migita, S.; Morita, Y.; et al. Comprehensive Analysis of $\mathrm{I}_{\mathrm{on}}$ Variation in Metal Gate FinFETs for $20 \mathrm{~nm}$ and Beyond. In Proceedings of the IEEE International Electron Devices Meeting, Washington, DC, USA, 5-7 December 2011; pp. 517-520. 
19. Endo, K.; O’uchi, S.; Ishikawa, Y.; Liu, Y.X.; Matsukawa, T.; Sakamoto, K.; Tsukada, J.; Yamauchi, H.; Masahara, M. Correlative Analysis between Characteristics of 30-nm L $\mathrm{L}_{\mathrm{G}}$ FinFETs and SRAM Performance. In Proceedings of the IEEE International Electron Devices Meeting, Washington, DC, USA, 8-10 December 2011; pp. 761-764.

20. Liu, Y.X.; Kamei, T.; Matsukawa, T.; Endo, K.; O’uchi, S.; Tsukada, J.; Yamauchi, H.; Ishikawa, Y.; Hayashida, T.; Sakamoto, K.; et al. Varaiability Analysis of Scaled Crystal Channel and Poly-Si Channel FinFETs. IEEE Trans. Electron Devices 2012, 59, 573-581.

21. Matsukawa, T.; Liu, Y.X.; Mizubayashi, W.; Tsukada, J.; Yamauchi, H.; Endo, K.; Ishikawa, Y.; O'uchi, S.; Ota, H.; Migita, S.; et al. Suppressing $\mathrm{V}_{\mathrm{t}}$ and $\mathrm{G}_{\mathrm{m}}$ Variability of FinFETs Using Amorphous Metal Gates for $14 \mathrm{~nm}$ and Beyond. In Proceedings of the IEEE International Electron Devices Meeting, San Fransico, CA, USA, 10-12 December 2012; pp. 175-178.

22. Endo, K.; O’uchi, S.; Matsukawa, T.; Liu, Y.X.; Sakamoto, K.; Mizubayashi, W.; Migita, S.; Morita, Y.; Ota, H.; Suzuki, E.; et al. Enhancing SRAM Performance by Advanced FinFET Device and Circuit Technology Collaboration for $14 \mathrm{~nm}$ Node and Beyond. In Proceedings of the Symposium on VLSI Technology, Kyoto, Japan, 11-13 June 2013; pp. 214-215.

23. Specht, M.; Dorda, U.; Dreeskornfeld, L.; Kretz, J.; Hofmann, F.; Stadele, M.; Luyken, R.J.; Rosner, W.; Reisinger, H.; Landgraf, E.; et al. $20 \mathrm{~nm}$ Tri-Gate SONOS Memory Cells with Multi-Level Operation. In Proceedings of the IEEE International Electron Devices Meeting, San Fransico, CA, USA, 13-15 December 2004; pp. 1083-1085.

24. Cho, E.-S.; Lee, C.-H.; Kim, T.-Y.; Sung, S.-K.; Cho, B.K.; Lee, C.; Cho, H.J.; Roh, Y.; Park, D.; Kim, K.; et al. Hf-Silicate Inter-Poly Dielectric Technology for Sub $70 \mathrm{~nm}$ Body Tied FinFET Flash Memory. In Proceedings of the Symposium on VLSI Technology, Kyoto, Japan, 14-16 June 2005; pp. 208-209.

25. Kim, S.; Kim, W.; Hyun, J.; Byun, S.; Koo, J.; Lee, J.; Cho, K.; Lim, S.; Park, J.; Yoo, I.K.; et al. Paired FinFET Charge Trap Flash Memory for Vertical High Density Storage. In Proceedings of the Symposium on VLSI Technology, Honolulu, HI, USA, 13-15 June 2006; pp. 104-105.

26. Cho, E.-S.; Kim, T.Y.; Cho, B.-K.; Lee, C.-H.; Lee, J.-J.; Fayrushin, A.; Lee, C.; Park, D.; Ryu, B.-I. Technology Breakthrough of Body-Tied FinFET for Sub $50 \mathrm{~nm}$ NOR Flash Memory. In Proceedings of Symposium on VLSI Technology, Honolulu, HI, USA, 13-15 June 2006; pp. 110-111.

27. Lee, S.H.; Lee, J.J.; Choe, J.D.; Cho, E.S.; Ahn, Y.J.; Hwang, W.; Kim, T.; Kim, W.J.; Yoon, Y.B.; Jang, D.; et al. Improved Post-Cycling Characteristics of FinFET NAND Flash. In Proceedings of the IEEE International Electron Devices Meeting, San Fransico, CA, USA, 11-13 December 2006; pp. 33-36.

28. Sung, S.-K.; Lee, S.-H.; Choi, B.Y.; Lee, J.J.; Choe, J.-D.; Cho, E.S.; Ahn, Y.J.; Choi, D.; Lee, C.-H.; Kim, D.H.; et al. SONOS-Type FinFET Device Using $\mathrm{P}^{+}$Poly-Si Gate and High-k Blocking Dielectric Integrated on Cell Array and GSL/SSL for Multi-Gigabit NAND Flash Memory. In Proceedings of the Symposium on VLSI Technology, Honolulu, HI, USA, 13-15 June 2006; pp. 106-107. 
29. Ahn, Y.-J.; Choe, J.-D.; Lee, J.J.; Choi, D.; Cho, E.S.; Choi, B.Y.; Lee, S.-H.; Sung, S.-K.; Lee, C.-H.; Cheong, S.H.; et al. Trap Layer Engineered FinFET NAND Flash with Enhanced Memory Window. In Proceedings of the Symposium on VLSI Technology, Honolulu, HI, USA, 13-15 June 2006; pp. 108-109.

30. Friederich, C.; Specht, M.; Lutz, T.; Hofmann, F.; Dreeskornfeld, L.; Weber, W.; Kretz, J.; Melde, T.; Rosner, W.; Landgraf, E.; et al. Multi-Level $\mathrm{p}^{+}$Tri-Gate SONOS NAND String Arrays. In Proceedings of the IEEE International Electron Devices Meeting, San Fransico, CA, USA, 11-13 December 2006; pp. 963-966.

31. Razafindramora, J.; Perniola, L.; Jahan, C.; Scheiblin, P.; Gely, M.; Vizioz, C.; Carabasse, C.; Boulanger, F.; Salvo, B.D.; Lombardo, S.; et al. Low Voltage Hot-Carrier Programming of Ultra-Scaled SOI Fin Flash Memories. In Proceedings of the European Solid-State Device Research Conference, Munich, Germany, 11-13 September 2007; pp. 414-417.

32. Endo, T.; Kinoshita, K.; Tanigami, T.; Wada, Y.; Sato, K.; Kazuya, K.; Yamada, K.; Yokoyama, T.; Takeuchi, N.; Tanaka, K.; et al. Novel Ultra High Density Flash Memory with A Stacked-Surrounding Gate Transistor (S-SGT) Structured Cell. In Proceedings of the IEEE International Electron Devices Meeting, Washington, DC, USA, 2-5 December 2001; pp. 33-35.

33. Goveoreanu, B.; Wellekens, D.; Haspeslagh, L.; Vos, J.D.; Houdt, J.V. Investigation of the Low-Field Leakage Through High-k Interpoly Dielectric Stacks and Its Impact on Nonvolatile Memory Data Retention. In Proceedings of the IEEE International Electron Devices Meeting, San Fransico, CA, USA, 11-13 December 2006; pp. 479-482.

34. Lee, C.H.; Choi, K.I.; Cho, M.K.; Song, Y.H.; Park, K.C.; Kim, K. A Novel SONOS Structure of $\mathrm{SiO}_{2} / \mathrm{SiN} / \mathrm{Al}_{2} \mathrm{O}_{3}$ with TaN Metal Gate for Multi-Giga Bit Flash Memories. In Proceedings of the IEEE International Electron Devices Meeting, Washington, DC, USA, 8-10 December 2003; pp. 613-616.

35. Kamei, T.; Liu, Y.X.; Matsukawa, T.; Endo, K.; O’uchi, S.; Tsukada, J.; Yamauchi, H.; Ishikawa, Y.; Hayashida, T.; Sakamoto, K.; et al. Comparative Study of Tri-Gate Flash Memories with Split and Stack Gates. In Proceedings of the IEEE International SOI Conference, Tempe, AZ, USA, 3-6 October 2011; pp. 294-295.

36. Kamei, T.; Liu, Y.X.; Matsukawa, T.; Endo, K.; O’uchi, S.; Tsukada, J.; Yamauchi, H.; Ishikawa, Y.; Hayashida, T.; Sakamoto, K.; et al. Demonstration of Split-Gate Type Trigate Flash Memory with Highly Suppressed Over-Erase. IEEE Electron Device Lett. 2012, 33, 345-347.

37. Kamei, T.; Liu, Y.X.; Matsukawa, T.; Endo, K.; O’uchi, S.; Tsukada, J.; Yamauchi, H.; Ishikawa, Y.; Hayashida, T.; Sakamoto, K.; et al. Fabrication and Characterization of NOR-Type Tri-Gate Flash Memory with Improved Inter-Poly Dielectric Layer by Rapid Thermal Oxidation. Jpn. J. Appl. Phys. 2012, 51, doi:10.1143/JJAP.51.06FE19.

38. Liu, Y.X.; Guo, R.F.; Kamei, T.; Matsukawa, T.; Endo, K.; O’uchi, S.; Tsukada, J.; Yamauchi, H.; Ishikawa, Y.; Hayashida, T.; et al. Experimental Study of Floating-Gate-Type Metal-Oxide-Semiconductor Capacitors with Nanosize Triangular Cross-Sectional Tunnel Areas for Low Operating Voltage Flash Memory Application. Jpn. J. Appl. Phys. 2012, 51, doi:10.1143/JJAP.51.06FF01. 
39. Liu, Y.X.; Kamei, T.; Matsukawa, T.; Endo, K.; O’uchi, S.; Tsukada, J.; Yamauchi, H.; Ishikawa, Y.; Hayashida, T.; Sakamoto, K.; et al. Direct Comparison of Electrical Characteristics for Double-Gate and Tri-Gate Flash Memories. In Proceedings of the Extended Abstracts of International Conference on Solid State Devices and Materials, Nagoya, Japan, 28-30 September 2011; pp. 985-986.

40. Liu, Y.X.; Kamei, T.; Matsukawa, T.; Endo, K.; O’uchi, S.; Tsukada, J.; Yamauchi, H.; Ishikawa, Y.; Hayashida, T.; Sakamoto, K.; et al. Fabrication of Floating-Gate-Type Fin-Channel Double- and Tri-Gate Flash Memories and Comparative Study of Their Electrical Characteristics. Jpn. J. Appl. Phys. 2012, 51, doi:10.1143/JJAP.51.04DD03.

41. Liu, Y.X.; Kamei, T.; Matsukawa, T.; Endo, K.; O’uchi, S.; Tsukada, J.; Yamauchi, H.; Ishikawa, Y.; Hayashida, T.; Sakamoto, K.; et al. Gate Structure Dependence of Variability in Polycrystalline Silicon Fin-Channel Flash Memories. Jpn. J. Appl. Phys. 2013, 52, doi:10.7567/JJAP.52.06GE01.

42. Liu, Y.X.; Matsukawa, T.; Endo, K.; O’uchi, S.; Tsukada, J.; Yamauchi, H.; Ishikawa, Y.; Mizubayashi, W.; Morita, Y.; Migita, S.; et al. Comparative Study of TiN Metal Gate and Poly-Si Gate Charge-Trapping Type FinFET Flash Memories. In Proceedings of the International Silicon Nanoelectronics Workshop, Kyoto, Japan, 11-14 June 2013; pp. 9-10.

43. Liu, Y.X.; Matsukawa, T.; Endo, K.; O’uchi, S.; Tsukada, J.; Yamauchi, H.; Ishikawa, Y.; Mizubayashi, W.; Morita, Y.; Migita, S.; et al. Charge Trapping Type FinFET Flash Memory with $\mathrm{Al}_{2} \mathrm{O}_{3}$ Blocking Layer. In Proceedings of the IEEE SOI-3D-Subthreshold Microelectronics Technology Unified Conference, Monterey, CA, USA, 7-10 October 2013.

44. Liu, Y.X.; Ishii, K.; Masahara, M.; Tsustumi, T.; Takashima, H.; Yamauchi, H.; Suzuki, E. Cross-Sectional Channel Shape Dependence of Short-Channel Effects in Fin-Type Double-Gate Metal Oxide Semiconductor Field-Effect Transistors. Jpn. J. Appl. Phys. 2004, 43, 2151-2155.

45. Liu, Y.X.; Kijima, S.; Sugimata, E.; Masahara, M.; Endo, K.; Ishii, K.; Matsukawa, T.; Takashima, H.; Yamauchi, H.; Takanashi, Y.; et al. Investigation of the TiN Gate Electrode with Tunable Work Function and Its Application for FinFET Fabrication. IEEE Trans. Nanotechnol. 2006, 5, 723-730.

46. Liu, Y.X.; Kamei, T.; Endo, K.; O’uchi, S.; Tsukada, J.; Yamauchi, H.; Hyashida, T.; Ishikawa, Y.; Mtsukawa, T.; Sakamoto, K.; et al. Nanoscale Wet Etching of Physical-Vapor-Deposited Titanium Nitride and Its Application to Sub-30-nm-Gate-Length Fin-Type Double-Gate Metal-Oxide-Semiconductor Field-Effect Transistor Fabrication. Jpn. J. Appl. Phys. 2010, 49, doi:10.1143/JJAP.49.06GH18.

47. Liu, Y.X.; Matsukawa, T.; Endo, K.; O’uchi, S.; Sakamoto, K.; Tsukada, J.; Ishikawa, Y.; Yamauchi, H.; Masahara, M. Investigation of Low-Energy Tilted Ion Implantation for Fin-Type Double-Gate Metal-Oxide-Semiconductor Field-Effect Transistor Extension Doping. Jpn. J. Appl. Phys. 2010, 49, doi:10.1143/JJAP.49.04DC18.

(C) 2014 by the authors; licensee MDPI, Basel, Switzerland. This article is an open access article distributed under the terms and conditions of the Creative Commons Attribution license (http://creativecommons.org/licenses/by/3.0/). 